\title{
Observation of near-inertial wave reflections within the thermostad layer of an anticyclonic mesoscale eddy
}

\author{
Sang-Shin Byun, ${ }^{1}$ Jong Jin Park, ${ }^{2}$ Kyung-Il Chang, ${ }^{1}$ and Raymond W. Schmitt ${ }^{2}$ \\ Received 30 October 2009; accepted 14 December 2009; published 15 January 2010.
}

[1] Moored current observations in the southwestern East/ Japan Sea of 16.5 months duration clearly captured two episodes of downward phase propagation (upward energy propagation) of near-inertial waves (NIWs). Time series of temperature and velocity from the mooring and ancillary information indicate that the mooring was located near the center of an anticyclonic eddy during these events. Considering the typical vertical structure of quasipermanent eddy features in the region, the observed downward phase propagation appeared to occur within the seasonal thermocline and upper thermostad of the anticyclonic mesoscale eddy. Ray tracing simulation of NIW using the observed subinertial currents suggests that the upward energy propagation is caused by the reflection of the NIWs within the thermostad of the anticyclonic eddy, where the effect of the vertical shear of subinertial horizontal currents is larger than the buoyancy effect in controlling the propagation of NIWs. Citation: Byun, S.-S., J. J. Park, K.-I. Chang, and R. W. Schmitt (2010), Observation of near-inertial wave reflections within the thermostad layer of an anticyclonic mesoscale eddy, Geophys. Res. Lett., 37, L01606, doi:10.1029/2009GL041601.

\section{Introduction}

[2] Internal gravity waves are thought to play an important role in the generation of turbulence and mixing in the ocean interior [Kunze, 1985; Hibiya et al., 1996]. The mixing caused by the breaking of internal gravity waves affects pollutant dispersal, marine productivity, and global climate [Alford, 2003]. Particularly, near-inertial waves (NIWs) can be generated by various forcing mechanisms but wind forcing is mainly responsible for the generation of NIWs in the surface mixed layer [Pollard and Millard, 1970]. The wind scale, mixed layer depth, and buoyancy frequency $(N)$ are crucial factors that control the downward energy propagation at the base of the mixed layer [Park et al., 2005; Park et al., 2009]. However, below the mixed layer, subinertial currents can play an important role in NIW propagation. Indeed, under weak stratification, the vertical shear of the subinertial currents significantly influences the propagation of NIWs and can reflect them to the sea surface [Merrifield and Pinkel, 1996].

[3] Reports have been given of an interaction of NIWs with the vorticity field of mesoscale eddies or currents

\footnotetext{
${ }^{1}$ School of Earth and Environmental Sciences and Research Institute of Oceanography, Seoul National University, Seoul, Korea.

${ }^{2}$ Department of Physical Oceanography, Woods Hole Oceanographic Institution, Woods Hole, Massachusetts, USA.
}

Copyright 2010 by the American Geophysical Union. 0094-8276/10/2009GL041601\$05.00
[Kunze, 1985; Toole and Schmitt, 1987; Kunze et al., 1995]. When NIWs are generated within an anticyclonic eddy, they can have frequencies below the local Coriolis frequency, and thus cannot propagate out of the eddy but will be trapped instead [Kunze et al., 1995].

[4] Mesoscale eddies are ubiquitous features in the East/ Japan Sea (East Sea hereafter), especially in the southern region due to the meandering of currents [e.g., Chang et al., 2004]. In the Ulleung Basin of the southwestern East Sea (Figure 1a), a quasi-stationary anticyclonic eddy, called the Ulleung Warm Eddy (UWE hereafter) is frequently observed. The UWE has a mean diameter of about $100 \mathrm{~km}-200 \mathrm{~km}$ with a signature down to a depth of $400 \mathrm{~m}$ or even deeper [Shin et al., 2005]. Figure 1b shows a meridional temperature section across the UWE in November 2000 [Kang et al., 2004], taken during the same season as in 2003, the period we are focusing on in this paper. The section shows a layer of homogeneous temperature, called a thermostad, with a temperature range of $10-11^{\circ} \mathrm{C}$, extending from $95 \mathrm{~m}$ to $185 \mathrm{~m}$ depth at the eddy center. The thermostad is capped by a seasonal thermocline during this season. The $N$ value in the thermostad $\left(\sim 0.003 \mathrm{~s}^{-1}\right.$, Figure 1c) is about 6 times smaller than that outside the eddy $\left(\sim 0.018 \mathrm{~s}^{-1}\right.$, Figure $\left.1 \mathrm{c}\right)$.

[5] In this paper, we will provide the first observational evidence of NIW reflection within the seasonal thermocline and thermostad of an anticyclonic mesoscale eddy using data from moored current measurements, and suggest the possibility that the unique buoyancy and shear structure of the thermostad is responsible for the NIW reflection. NIW reflections near the upper thermostad of an anticyclonic mesoscale eddy have been rarely documented with observations due to the difficulty of obtaining continuous time series data within an eddy. Because of the quasi-stationary nature of the UWE which is thought to be controlled by topography, our long-term moored measurements were able to capture the behavior of NIW propagation through an anticyclonic eddy.

\section{Data}

[6] A moored current meter measurement was conducted in a depth of $2275 \mathrm{~m}$ in the Ulleung Basin of the southwestern East Sea (Site EC1 in Figure 1a) between November 2002 and April 2004. The mooring was equipped with an upward-looking acoustic Doppler current profiler (ADCP) at $160 \mathrm{~m}$ depth and six RCM-type current meters with temperature sensors at $200 \mathrm{~m}, 360 \mathrm{~m}, 1000 \mathrm{~m}, 1360 \mathrm{~m}$, $1685 \mathrm{~m}$, and $2255 \mathrm{~m}$ depth levels. The ADCP recorded temperature at $160 \mathrm{~m}$ and currents every hour at $4 \mathrm{~m}$ intervals from $17 \mathrm{~m}$ to $153 \mathrm{~m}$. The ADCP current records shallower than $53 \mathrm{~m}$ are somewhat contaminated by the lack of scatterers during daylight hours, presumably due to the 
(a)

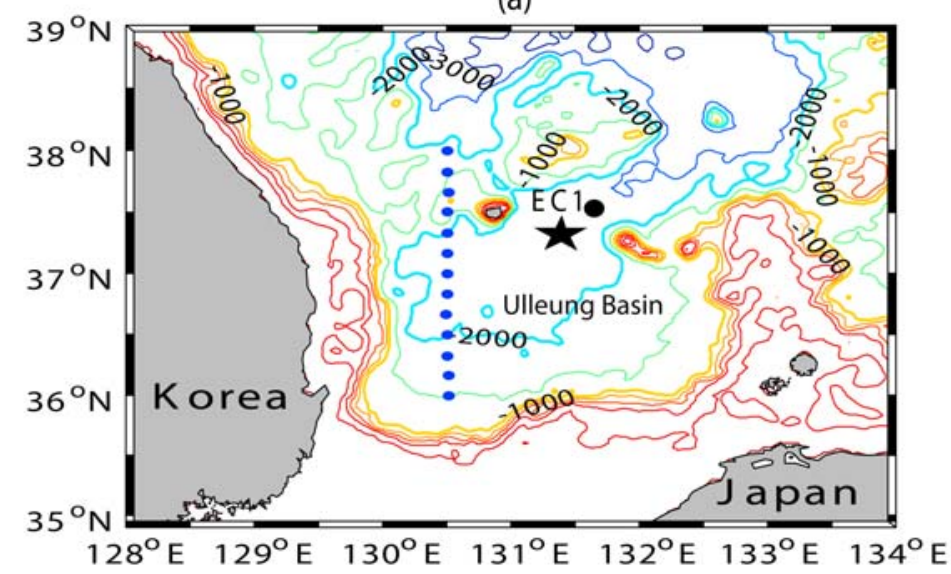

(b)

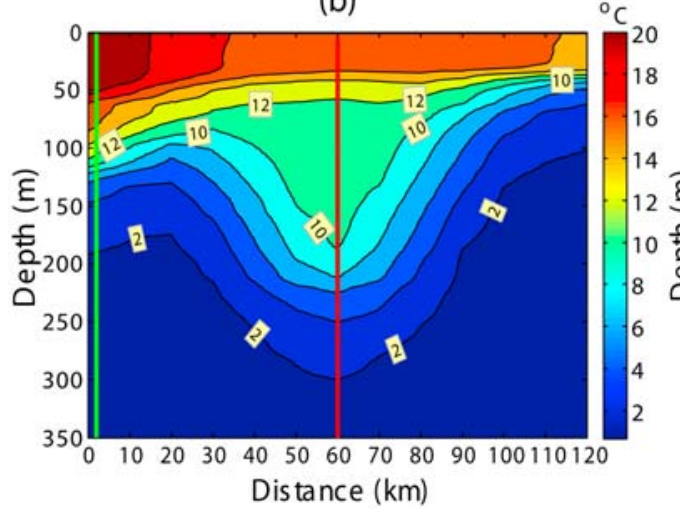

(c)

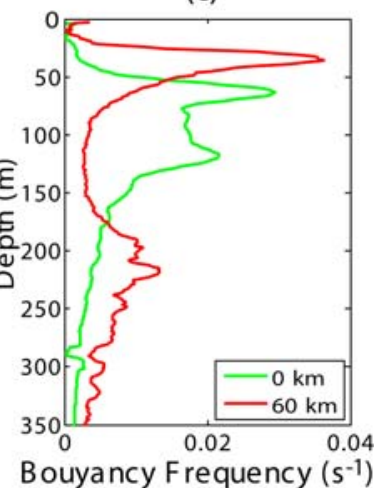

Figure 1. (a) Position of current meter mooring EC1 (star symbol) in the Ulleung Basin of the southwestern East Sea. Black dot denotes Argo float position on 7 October 2003. Background contours show isobaths. (b) Vertical temperature section across the anticyclonic Ulleung Warm Eddy in November 2000. Stations are shown with blue dots in Figure 1a, and the distance is measured from the southernmost station. (c) Buoyancy frequencies in the eddy center (red line) and outside the eddy (green line) at two locations shown in Figure $1 \mathrm{~b}$ with the same colors.

diurnal migration of marine biota. The current meters recorded temperatures and currents every 30 minutes at each depth level. Measured currents are decomposed into east-west (u) and north-south (v) components, and bandpass filtered with a 4th order Butterworth filter to investigate NIW phase propagation. The filtered band is $0.9 f \sim$ $1.1 f$ from the inertial frequency at $\mathrm{EC} 1$ where $f$ is the local Coriolis frequency.

\section{Results}

\subsection{Warm Eddy Event}

[7] During the entire observation period, we found three energetic NIW amplitude events ( $>15 \mathrm{~cm} / \mathrm{s}$ at $53 \mathrm{~m}$ depth) in July, September, and late October-late November, 2003 (Figure 2a). According to unfiltered temperature time series observed at three depth levels between June and November 2003 (Figure 2b), temperature at $160 \mathrm{~m}$ increased sharply up to $9^{\circ} \mathrm{C}$ after mid August 2003, and at the same time temperature at $200 \mathrm{~m}$ also gradually increased up to $9^{\circ} \mathrm{C}$. Temperatures at $160 \mathrm{~m}$ and $200 \mathrm{~m}$ became the same after mid October, remained constant at around $9^{\circ} \mathrm{C}$ from mid October to late November, and temperature at $360 \mathrm{~m}$ also increased up to $4^{\circ} \mathrm{C}$ during this period. The temperature time series in Figure 2b suggests that an anticyclonic eddy, most likely the UWE, passed by the mooring EC1. Maps of sea surface height and sea surface temperature measured by satellites (not shown) also confirm that the eddy migrated from east to west, and its center was placed near the mooring from late October to late November. The variation of observed subinertial currents is also consistent with the eddy movement near the mooring site described above. Prior to the arrival of the eddy center at EC1, strong $\left(>70 \mathrm{~cm} \mathrm{~s}^{-1}\right)$ northward subinertial currents were observed as the eddy's western periphery approached EC1. When EC1 was located near the eddy center, the subinertial currents became weak $\left(<20 \mathrm{~cm} \mathrm{~s}^{-1}\right)$. More details on the fluctuations of subinertial currents due to the passage of the eddy are described by Kim et al. [2009]. Additionally, an Argo float profiling the eddy structure northeast of EC1 (Figure 1a) on October 7, 2003 revealed the thermostad layer between $100 \mathrm{~m}$ and $200 \mathrm{~m}$ (Figure 2c). Figure $2 \mathrm{~d}$ shows $N$ from the Argo float, and daily averaged vertical shear profiles on October 30 , which provides a good example of vertical shear while the eddy was present. The vertical shear in the north-south component of velocity is about 13 times smaller than $N$ at $53 \mathrm{~m}$, but only $3 \sim 4$ times smaller below $80 \mathrm{~m}$. 
(a)

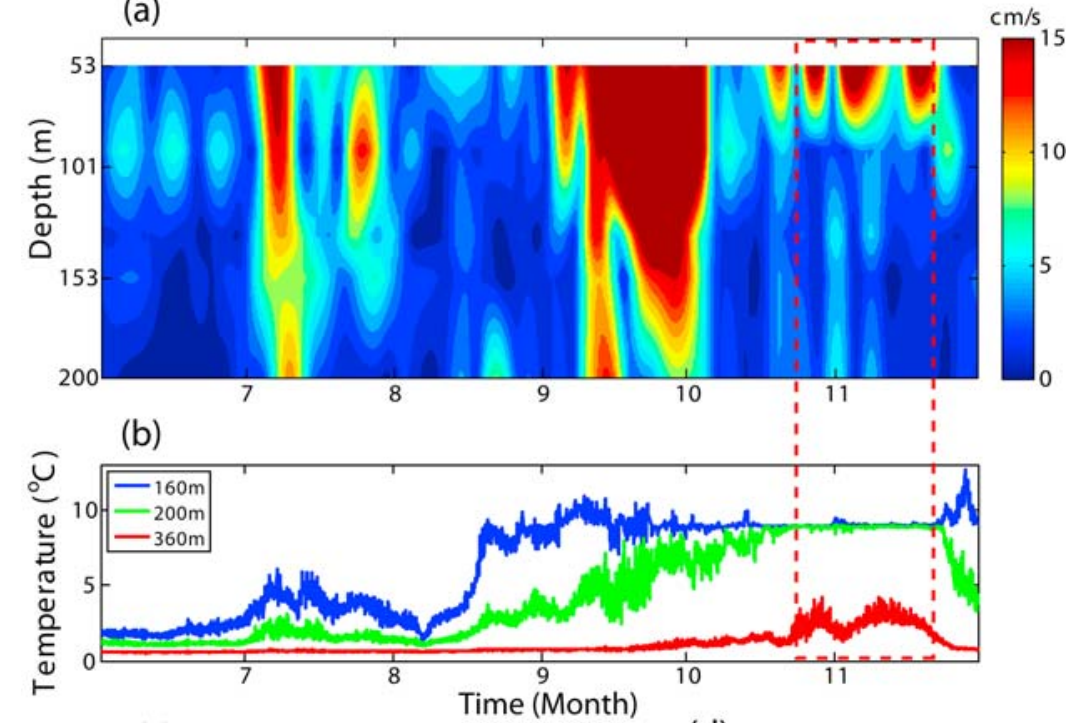

(c)

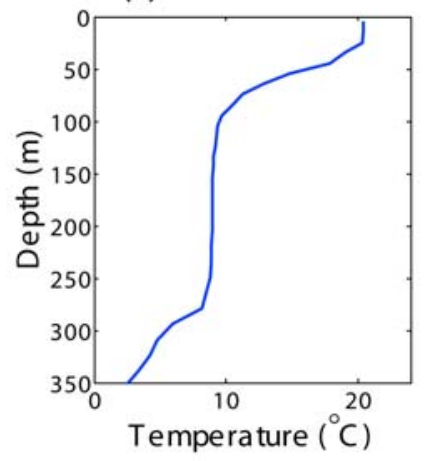

(d)

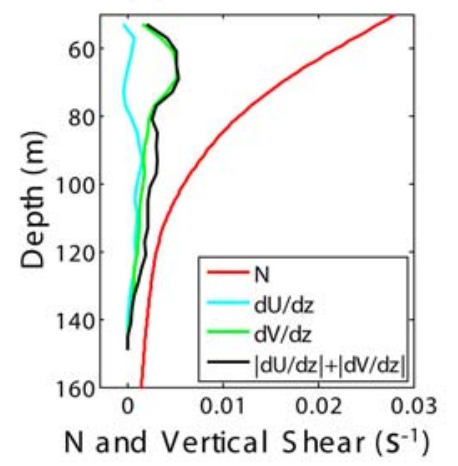

Figure 2. (a) Amplitude of NIWs $\left(\sqrt{\mathrm{u}^{2}+\mathrm{v}^{2}}\right)$ calculated from band-pass filtered $\mathrm{u}$ and v during June-November, 2003. (b) Unfiltered temperature time series at $160 \mathrm{~m}, 200 \mathrm{~m}$ and $360 \mathrm{~m}$. Red-dotted box in Figures 2a and 2b indicates the period when the mooring was placed near the center of the eddy during October 23 to November 20. (c) Temperature profile from Argo float data observed near the center of the eddy on 7 October 2003, when the eddy was at the location shown with black dot in Figure 1a. (d) Buoyancy frequency observed near the center of the eddy by an Argo float on 7 October 2003 (red). Daily averaged vertical shears of east-west (cyan) and north-south (green) components, and the maximum possible vertical shear $(|d U / d z|+|d V / d z|)$ (black).

\subsection{Observed Downward Phase Propagation of Near-Inertial Waves}

[8] Among the three energetic NIW amplitude events, our main focus is the third event (red-dotted box in Figure 2), when the mooring was located near the center of the eddy, in the depth range between $53 \mathrm{~m}$ and $153 \mathrm{~m}$ covered by ADCP. The vertical NIW amplitude distribution is very different from the previous two events. NIW amplitudes of the previous two events gradually decrease with depth $(>10 \mathrm{~cm} / \mathrm{s}$ at $100 \mathrm{~m})$, while, in the third event, they decrease sharply and no significant NIW amplitude is found below $70 \mathrm{~m}(<5 \mathrm{~cm} / \mathrm{s}$ at $100 \mathrm{~m})$.

[9] In the upper $100 \mathrm{~m}$, the band-pass filtered u-component shows clearly downward phase propagation (i.e., upward energy propagation) from October 28 to 31 after nearly inphase or upward phase propagation (i.e., downward energy propagation) during October 26-27 (Figure 3a). The downward phase propagation is again obvious from November 7 to 10 after upward phase propagation during November 3-6.
Below $100 \mathrm{~m}$, in-phase propagation appears from October 30 to November 2, and also from November 6 to 9 . Figure $3 \mathrm{~b}$ shows the depth where the inertial phase becomes $\pi / 2$ relative to the inertial current vector at $53 \mathrm{~m}$. This figure presents a clear picture of the vertical phase change in inertial currents. The depths during the downward phase propagation period (red line) appear shallower than those in the upward phase propagation period (blue line). It implies that the NIW in the downward phase propagation likely has shorter vertical scales or higher wave numbers which could effectively contribute to turbulent mixing. Details on this issue will be discussed in section 5 .

[10] The vertical stratification in the thermostad is fairly weak, while the observed vertical shear of the subinertial currents in the upper thermostad (around $100 \mathrm{~m}$ ) is comparable with it $(1 / 3 \sim 1 / 4 N$, Figure $2 \mathrm{~d})$, suggestive of the importance of the vertical shear to NIW propagation inside the eddy. The observed upward energy propagations of NIWs are thought to be caused by the NIW reflection, 

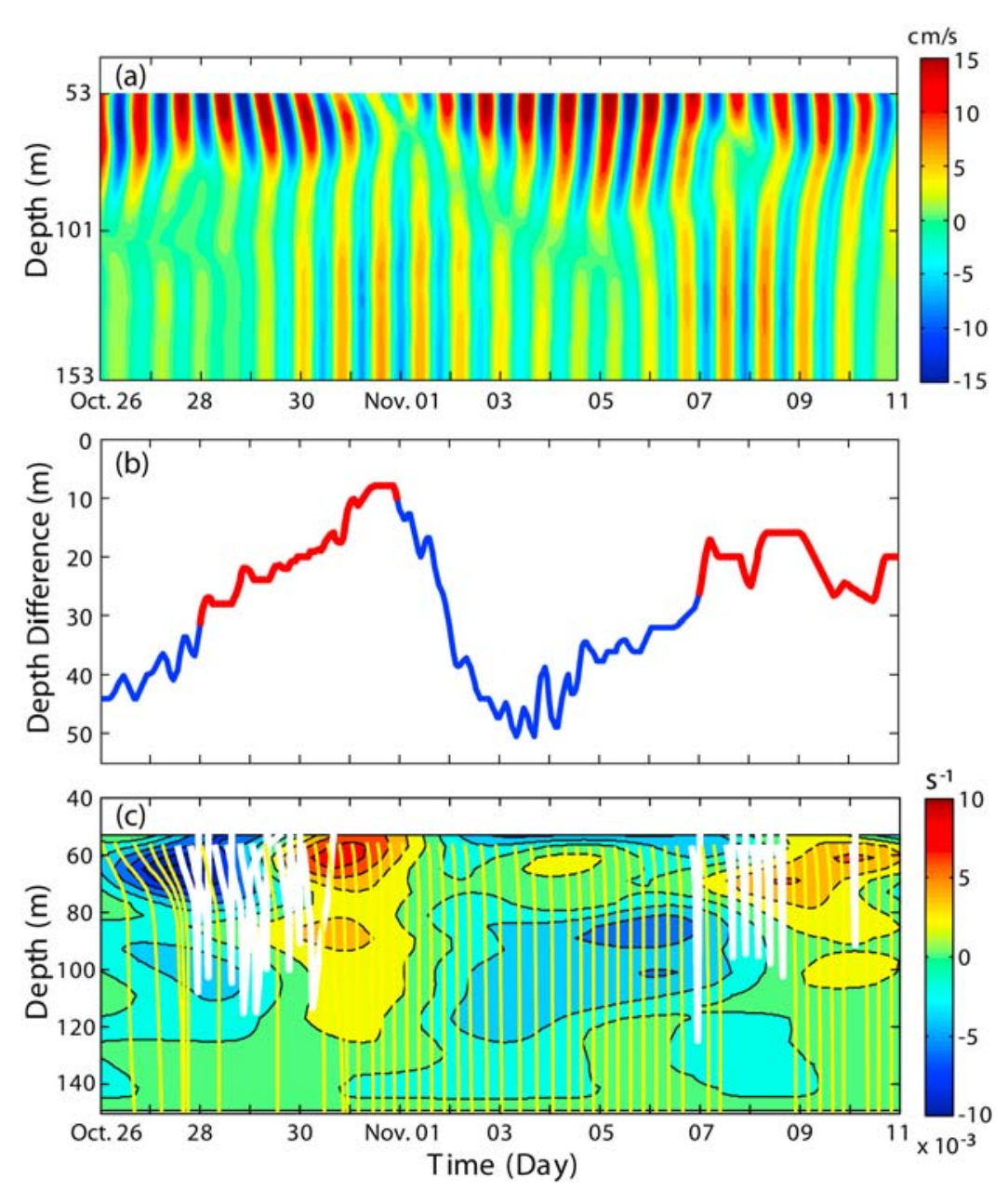

Figure 3. (a) Band-pass filtered u-component during the eddy event period. (b) Depths where inertial phase become $\pi / 2$ relative to inertial current vectors at $53 \mathrm{~m}$. (c) Calculated ray paths from a ray-tracing model. White and yellow lines denote reflecting and penetrating ray trajectories, respectively. Background color map represents total vertical shears $(d U / d z+d V / d z)$.

which will be addressed in the following section using a scaling analysis and a simple ray tracing model.

\section{Discussion}

\subsection{Scaling Analysis}

[11] Under the thermal wind relationship, the vertical shear of subinertial currents are directly related to horizontal density gradients. When a water parcel moves on a plane contiguous with the NIW group velocity vector which makes an angle to the isopycnal surfaces, it feels a density contrast, called the effective buoyancy, with a larger angle corresponding to a greater density contrast. Near the upper thermostad of UWE, the effective buoyancy can become important in NIW propagation due to the weak stratification and tilting of isopycnals.

[12] In a geostrophic shear, the vertical group velocity of a NIW [Kunze, 1985] is given as:

$$
\mathrm{Cg}_{\mathrm{z}}=\frac{\partial \omega_{0}}{\partial k_{z}} \approx \frac{-N^{2} k_{H}^{2}}{f k_{z}^{3}}-\frac{1}{k_{z}^{2}}\left(\frac{\partial U}{\partial z} k_{y}-\frac{\partial V}{\partial z} k_{x}\right)
$$

where $\mathrm{Cg}_{\mathrm{z}}$ is the NIW vertical group velocity, $\omega_{0}$ is the NIW intrinsic frequency, $k_{x}, k_{y}$, and $k_{z}$ are wave numbers in the horizontal and vertical directions, $k_{H}=\sqrt{k_{x}^{2}+k_{y}^{2}}$, and $U$ and $V$ are the subinertial current velocities. The vertical coordinate, $z$, is positive upwards. The second term on the right hand side of (1) is the effective buoyancy term.

[13] The effective buoyancy term depends on the direction of wave number vector. In order to examine whether the buoyancy environment within the UWE could support a NIW reflection, the maximum possible vertical shear is estimated assuming a horizontally isotropic wave vector. Then, the vertical group velocity of a NIW becomes

$$
\mathrm{Cg}_{\mathrm{z}}=\frac{-N^{2} k_{H}^{2}}{f k_{z}^{3}}+\frac{\left|k_{x}\right|}{k_{z}^{2}}\left(\left|\frac{\partial U}{\partial z}\right|+\left|\frac{\partial V}{\partial z}\right|\right) \text {. }
$$

To compare the size of two terms on the right hand side of (2), a non-dimensional parameter $\mu$ is defined as

$$
\mu \equiv \frac{f\left|k_{x}\right|\left|k_{z}\right|}{N^{2} k_{H}^{2}}\left(\left|\frac{\partial U}{\partial z}\right|+\left|\frac{\partial V}{\partial z}\right|\right) .
$$


Only downward energy propagation occurs, when $\mu$ is smaller than unity. If $\mu$ is larger than unity, equation (3) dictates that upward energy propagation is possible. To gain an insight, if we assume that the NIW's horizontal and vertical wavelengths are $40 \mathrm{~km}$ and $100 \mathrm{~m}$, respectively (justified in the next section), $N=0.5 \times 10^{-2} \mathrm{~s}^{-1}$ at $100 \mathrm{~m}$ from Figure $2 \mathrm{~d}$, and $f=8.84 \times 10^{-5} \mathrm{~s}^{-1}$ at $\mathrm{EC} 1$, then the non-dimensional $\mu$ parameter becomes greater than unity when the vertical shear is larger than $0.1 \times 10^{-2} s^{-1}$ equivalent to $0.2 N$. If we use the $N$ value outside the eddy $\left(N=1.8 \times 10^{-2} \mathrm{~s}^{-1}\right)$ from Figure $1 \mathrm{c}, \mu$ becomes 0.077 with the same shear of $0.1 \times 10^{-2} s^{-1}$, and reflection does not occur whatever direction a NIW has. As shown in Figure $2 \mathrm{~d}$, the maximum possible vertical shear is around $0.25 \times$ $10^{-2} s^{-1}$ at $100 \mathrm{~m}$, then the non-dimensional parameter becomes $\mu=2.5$, that is strong enough to make NIWs reflect within the layer.

[14] Scaling arguments based on the observed buoyancy frequency and the vertical shear of subinertial currents suggest the possibility for NIW reflection to occur in the upper thermostad of the UWE. The length scales of NIW, however, vary not only along the NIW ray path but also with the initial wave characteristics, and signs of vertical shears also vary along the NIW ray path, so we now use a ray-tracing model to investigate the NIW propagation more in detail.

\subsection{Ray-Tracing Approach}

[15] A ray-tracing model is applied to investigate the propagation of NIWs in the upper thermostad of an anticyclonic eddy. The purpose of this simulation is to test the possibility of NIW reflection within the physical environment of the eddy characterized with the observed thermostad and strong vertical current shears, but not to give an exact reproduction of the observations. The equations for the wave position and wave number vector, and the dispersion relation given by Kunze [1985, his equations 12, 13,14] are

$$
\begin{gathered}
\frac{d \mathbf{r}}{d t}=\mathbf{C g}+\mathbf{V} \\
\frac{d \mathbf{k}}{d t}=-\nabla \omega \\
\omega=f_{\text {eff }}+\frac{N^{2} k_{H}^{2}}{2 f k_{z}^{2}}+\frac{1}{k_{z}}\left(\frac{\partial U}{\partial z} k_{y}-\frac{\partial V}{\partial z} k_{x}\right)+(\mathbf{k} \cdot \mathbf{V})=\text { constant }
\end{gathered}
$$

where $f_{\text {eff }}=f+\frac{\zeta}{2}=f+\frac{1}{2}\left(\frac{\partial V}{\partial x}-\frac{\partial U}{\partial y}\right), \nabla$ is the del operator, $\mathbf{r}=\left(r_{x}, r_{y}, r_{z}\right)$ is the wave's position, $\mathbf{V}=(U, V)$ is the subinertial current velocity, $\mathbf{k}=\left(k_{x}, k_{y}, k_{z}\right)$ is the wave number vector, $\mathbf{C g}=\left(C g_{x}, C g_{y}, C g_{z}\right)$ is the group velocity and $\omega$ is the Eulerian frequency.

[16] The parameters for the ray tracing model are constant relative vorticity $(\zeta)=-0.15 f$, vertically varying buoyancy frequency (red line in Figure 2d), and hourly values of 4-day low-pass filtered currents observed by the mooring. The relative vorticity value is based on an estimation from a rectified NIW frequency at $53 \mathrm{~m}$. The model calculates wave positions and wave numbers with prescribed initial wave characteristics. A NIW impinging from the northwest is imposed initially. The initial wavelengths are assumed as follows: a vertical wavelength of $100 \mathrm{~m}$ is approximately estimated from the vertical change of inertial phase (phase change of $\pi / 2$ within $\sim 25 \mathrm{~m}$ in Figure $3 \mathrm{~b}$ ); an initial horizontal wavelength of the NIW is assumed to be $40 \mathrm{~km}$ based on an estimation $(38 \mathrm{~km})$ in the subpolar front of the East Sea by Shcherbina et al. [2003]. The initial wavelengths we choose are the same as those used in the ray-tracing simulation based on the observation in the North Pacific Subpolar Front by Kunze [1985]. We attempted two other cases by changing the horizontal wavelength $(30 \mathrm{~km}$ and $50 \mathrm{~km}$ ), and the model showed similar results.

[17] The lines and background color map in Figure 3c are the computed ray-paths (yellow and thick white lines), and the total vertical shears, which becomes large in the upper thermostad. The results of the ray-tracing model agree reasonably well with the observed alternating upward and downward phase propagation of NIWs, although the ray solution provides only a qualitative assessment. Especially, the model simulates well the NIW reflections (thick white lines in Figure 3c) at the same time intervals as the observation (Figure 3a). Also, most of wave reflections appear near the high shear regions. This suggests that the observed NIW downward phase propagation is caused by the reflection of NIWs in the upper thermostad of the anticyclonic eddy due to a large vertical shear of horizontal subinertial currents and a relatively small buoyancy frequency. The highest shear regions, however, do not exactly match the reflection points, because the depths and times of reflections can depend on NIW wave number vectors varying with ray paths according to the vertical shear of horizontal subinertial currents, the buoyancy frequency, relative vorticity, and other factors.

\section{Summary and Conclusion}

[18] A new aspect of the interactions between NIWs and mesoscale eddies has been suggested by the observations presented in this paper, namely, NIW reflection in the upper thermostad layer of an eddy. This phenomenon is important because the weakly stratified layer within an eddy can prevent NIW energy from propagating downward, and reflect energy back to the surface instead.

[19] The scaling analysis and ray tracing model suggest that the NIW reflection can occur when the wave enters a thermostad layer with weak stratification but strong vertical shear in the subinertial currents. Since these episodes of upward energy propagation are observed only during the presence of an anticyclonic eddy with a thermostad layer, such eddies may be responsible for supplying a particular buoyancy environment favorable to NIW reflection. This is the first time that reflections of NIW within the thermostad of an anticyclonic eddy have been directly observed from a continuous time series.

[20] Anticyclonic mesoscale eddies observed in the Sargasso Sea also show the vertical shear increasing with depth near the upper thermostad layer [Brundage and Dugan, 1986]. This implies that our findings may be applied to mode water eddies observed in the North Atlantic and other 
oceans. Further studies would be required to more fully characterize NIW propagation within mesoscale eddies.

[21] Additionally, as discussed above, during the upward NIW reflection periods, vertical inertial phase changes more sharply than during the downward energy propagation periods, so we expect that its vertical wavelength would also be shorter. Jordi and Wang [2008] indicated that downward propagating free NIWs can be suppressed by bottom reflected NIWs and the interaction causes a cascade of energy toward small scales, wave breaking, and enhanced turbulence. Our observations of NIW reflection within the eddy raises the possibility that the reflected waves could interact with incoming waves and thus be converted into small scale waves, ultimately leading to turbulent mixing within the thermostad layer. Calculated Richardson number using highly-resolved CTD and ADCP data across the UWE in May 1999 [Chang et al., 2004] also shows small value $(<1 / 4)$ in the upper thermostad layer (not shown).

[22] Progress toward understanding the dynamics of NIW reflection and upper ocean mixing in an anticyclonic eddy will require more complete data sets than available in this instance. However, we do feel that these observations provide significant motivation to more closely examine the role of mesoscale eddies in NIW propagation and related mixing.

[23] Acknowledgments. The authors are grateful to Jae-Hun Park, John Toole, Tom Farrar, Young-Oh Kwon, and Yun-Bae Kim for kindly providing the ray tracing program and for helpful discussions. This work was supported by grants from the Ministry of Land, Transport, and Maritime Affairs (Ocean Climate Variability Program), and the US NSF, grant OCE-0647949 to RWS.

\section{References}

Alford, M. H. (2003), Redistribution of energy available for ocean mixing by long-range propagation of internal waves, Nature, 423, 159-162, doi:10.1038/nature01628.

Brundage, W. L., and J. P. Dugan (1986), Observations of an anticyclonic eddy $18^{\circ} \mathrm{C}$ water in the Sargasso Sea, J. Phys. Oceanogr., 16, 717-727, doi:10.1175/1520-0485(1986)016<0717:OOAAEO >2.0.CO;2.

Chang, K.-I., W. J. Teague, S. J. Lyu, H. T. Perkins, D.-K. Lee, D. R. Watts, Y.-B. Kim, D. A. Mitchell, C. M. Lee, and K. Kim (2004), Circulation and currents in the southwestern East/Japan Sea: Overview and review, Prog. Oceanogr., 61, 105-156, doi:10.1016/j.pocean.2004.06.005.

Hibiya, T., Y. Niwa, K. Nakajima, and N. Suginohara (1996), Direct numerical simulation of the roll-off range of internal wave shear spectra in the ocean, J. Geophys. Res., 101(C6), 14,123-14,129, doi:10.1029/ 96JC01001.

Jordi, A., and D.-P. Wang (2008), Near-inertial motions in and around the Palamós submarine canyon (NW Mediterranean) generated by a severe storm, Cont. Shelf Res., 28, 2523-2534, doi:10.1016/j.csr.2008.07.008.

Kang, J.-H., W.-S. Kim, K.-I. Chang, and J.-H. Noh (2004), Distribution of plankton related to the mesoscale physical structure within the surface mixed layer in the southwestern East Sea, Korea, J. Plankton Res., 26, 1515-1528, doi:10.1093/plankt/fbh140.

Kim, Y.-B., K.-I. Chang, K. Kim, J.-H. Park, and J.-H. Lee (2009), Vertical structure of low-frequency currents in the southwestern East Sea (Sea of Japan), J. Oceanogr., 65, 259-271, doi:10.1007/s10872-009-0024-x.

Kunze, E. (1985), Near-inertial wave propagation in geostrophic shear, J. Phys. Oceanogr., 15, 544-565, doi:10.1175/1520-0485(1985)015< 0544:NIWPIG>2.0.CO;2.

Kunze, E., R. W. Schmitt, and J. M. Toole (1995), The energy balance in a warm-core ring's near-inertial critical layer, J. Phys. Oceanogr., 25, $942-$ 957, doi:10.1175/1520-0485(1995)025<0942:TEBIAW $>2.0$. CO;2.

Merrifield, M. A., and R. Pinkel (1996), Inertial currents in the Beaufort Sea: Observations of response to wind and shear, J. Geophys. Res., 101(C3), 6577-6590, doi:10.1029/95JC03625.

Park, J. J., K. Kim, and B. A. King (2005), Global statistics of inertial motions, Geophys. Res. Lett., 32, L14612, doi:10.1029/2005GL023258.

Park, J. J., K. Kim, and R. W. Schmitt (2009), Global distribution of the decay time scale of mixed layer inertial motions observed by satellite tracked drifters, J. Geophys. Res., 114, C11010, doi:10.1029/ 2008JC005216.

Pollard, R. T., and R. C. Millard (1970), Comparison between observed and simulated wind-generated inertial oscillations, Deep Sea Res., 17, 813821 .

Shcherbina, A. Y., L. D. Talley, E. Firing, and P. Hacker (2003), Nearsurface frontal zone trapping and deep upward propagation of internal wave energy in the Japan/East Sea, J. Phys. Oceanogr., 33, 900-912, doi:10.1175/1520-0485(2003)33<900:NFZTAD>2.0.CO;2.

Shin, H.-R., C.-W. Shin, C. Kim, S.-K. Byun, and S.-C. Hwang (2005), Movement and structural variation of warm eddy WE92 for three years in the western East/Japan Sea, Deep Sea Res., Part II, 52, 1742-1762, doi:10.1016/j.dsr2.2004.10.004.

Toole, J. M., and R. W. Schmitt (1987), Small-scale structures in the northwest Atlantic subtropical front, Nature, 327, 47-49, doi:10.1038/ $327047 \mathrm{a} 0$.

S.-S. Byun and K.-I. Chang, School of Earth and Environmental Sciences, National University, 599 Gwanangno, Gwanak-gu, Seoul 151742, Korea. (kichang@snu.ac.kr)

J. J. Park and R. W. Schmitt, Department of Physical Oceanography, Woods Hole Oceanographic Institution, Woods Hole, MA 02543, USA. 